the following United Nations websites: household size - www.unstats.un.org/unsd/demographic/ sconcerns/housing/housing2.htm (median year for these data from different countries was 1991); density per room - www.unstats.un.org/unsd/ demographic/products/socind/housing.htm; and general population density - www.unstats.un.org/ unsd/demographic/products/dyb/dyb2006/Table03. pdf. Spearman's correlation coefficient $(\rho)$ was used to examine the relationship between elderly suicide rates and the household size, the general population density and the density of the number of people per room.

There were significant negative correlations between the average number of people living in a household and suicide rates in males aged 6574 years $(\rho=-0.39, \mathrm{P}=0.006)$, males aged $75+$ years $(\rho=-0.46, \mathbf{P}=0.001)$, females aged 65 74 years $(\rho=-0.53, \mathrm{P} ;<0.00001)$ and females aged $75+$ years $(\rho=-0.51, \mathrm{P}<0.00001)$ for 47 countries. There were no significant correlations between elderly suicide rates and general population density (data for 78 countries) and the density of people per household room (data for 36 countries).

The negative correlation between elderly suicide rates and household size confirms the findings of a recent study (Shah, 2009), which used a different data source for household size. However, the negative findings do not allow further clarification of the relative contribution of emotional and geographical proximity explanations to elderly suicide rates. The negative findings may be the result of the well-described methdological issues in ecological studies of elderly suicides (Shah, 2009). The emotional and geographical proximity explanations are both likely to contribute simultaneously to elderly suicides rather than be "either/or" explanations.

doi:10.1017/S1041610209991062

\section{Comparison of rates of suicide methods used by the elderly in England and Wales}

Because suicide rates have traditionally increased with age (Shah and De, 1998; Shah, 2007), the observed reduction in suicide rates among older people may be an important contributor to the U.K. government's target to reduce suicide rates in the general population by at least one-sixth of the 1996 baseline by 2010 (Department of Health, 1999). Previous studies have observed that suicide rates in older people have declined in both sexes over the 12-year period (1985-1996) and 24-year

\section{Conflict of interest}

None.

\section{References}

Kua, E. H., Ko, S. M. and Ng, T. P. (2003). Recent trends in elderly suicide rates in a multi-ethnic Asian city. International Fournal of Geriatric Psychiatry, 18, 533-536.

Liu, H., Wang, H. and Yang, M. (2006). Factors associated with an unusual increase in elderly suicide rate in Taiwan. International fournal of Geriatric Psychiatry, 21, 1219-1221.

Shah, A. K. (2009). The relationship between elderly suicide rates, household size and family structure: a cross-national study. International fournal of Psychiatry in Clinical Practice. Epublished ahead of print 22 May 2009; doi: $10.1080 / 13651500902887656$.

Yip, P. S. F. and Tan, R. C. E. (1998). Suicides in Hong Kong and Singapore: a tale of two cities. International fournal of Social Psychiatry, 44, 267-279.

Yip, P. S. F., Chi, I. and Yu, K. K. (1998). An epidemiological profile of elderly suicides in Hong Kong. International Fournal of Geriatric Psychiatry, 13, 631-637.

Yip, P. S. F., Callanan, C. and Yuen, H. P. (2000). Urban/rural and gender differentials in suicide rates: East \& West. Fournal of Affective Disorders, 57, 99-106.

\author{
AJit Shah, ${ }^{1}$ Tanuja Sinha ${ }^{2}$ AND \\ RAJESWARI MAKENA ${ }^{2}$ \\ ${ }^{1}$ Ageing, Ethnicity and Mental Health, University of \\ Central Lancashire, Preston and Consultant \\ Psychiatrist, West London Mental Health NHS Trust, \\ London, U.K. \\ ${ }^{2}$ West London Mental Health NHS Trust, London, \\ U.K. \\ Email: ajit.shah@wlmht.nhs.uk
}

period (1979-2002) in England and Wales (Hoxey and Shah, 2000; Shah et al., 2001), although the rates are still considerably higher than those among younger adults. It is believed that a better understanding of the methods used by older people for suicide may lead to the development of targeted preventative strategies, which are expected to meet the challenge of sustaining this observed decline in suicide rates among older people over time in England and Wales (Lindesay, 1991; Dennis and Lindesay, 1995).

Traditionally, elderly men use more violent methods of suicide, including hanging, strangulation and suffocation, shotgun and larger firearm discharge, and sharp objects (Shah and De, 1998; Harwood 
et al., 2000; Hoxey and Shah, 2000; Tadros and Salib, 2000; Salib and Green, 2003). Older women tend to use more passive methods of suicide, in particular drug overdose (Hoxey and Shah, 2000; Harwood et al., 2000; Tadros and Salib, 2000). In addition, Tadros and Salib (2000) found that older age groups tended to use methods which required less physical energy, and which they had access to, and that overall the most common method of suicide used by the elderly was poisoning by drug overdose, whereas hanging was the most common method for younger adults.

Data on suicides and open verdicts (pertaining to deaths from injury and poisoning), for the seven year period 2001-07, was ascertained from the Office of National Statistics (http://www.statistics. gov.uk/statbase/Product.asp?vlnk=618). Data on suicides and open verdicts were available for 21 fiveyear age-bands for both sexes between $<1$ year and $95+$ years for both sexes. These data were collapsed into the following age-bands for both sexes: (i) under the age of 65 years, and (ii) aged 65 years and over.

Standardized mortality ratios (SMRs) were calculated for each method of suicide in older men and women by using younger men and women respectively as the standard population. SMRs were also calculated for each method of suicide in older women by using older men as the standard population. An SMR of 1 implies that the mortality rate is the same as in the standard population. A number higher than 1 implies an increased mortality rate whereas a number below 1 implies a reduced mortality rate than in the standard population. The results are considered statistically significant if the 95\% confidence interval around the SMR does not include 1 .

There was a significantly higher rate of suicides in older men than women for the following methods: for hanging, strangulation and suffocation the SMR was 0.19 (95\% CI -0.04-0.42); for drowning and submersion the SMR was 0.53 (95\% CI 0.08-0.98); for other unspecified firearm discharge the SMR was 0.014 (95\% CI $-0.26-0.28)$; and for sharp objects the SMR was 0.17 (95\% CI -0.50-0.84). The rates for the total number of suicides were likewise significantly higher in older men than older women, with an SMR of 0.40 (95\% CI $0.22-0.58)$. The only method in which the SMRs were higher for older women than men were antiepileptic, sedativehypnotic, antiparkinsonism and psychotropic drugs not elsewhere classified; however, these did not reach statistical significance. The rates for total male suicides were significantly higher for older men than younger men, SMR 2.04 (95\% CI 1.28-2.80), and although there were no significant differences in total rates between older and younger women, rates were higher for older than younger women.

This study found that, overall, suicide rates among older people in England and Wales were higher in men than women, which supports previous observations (Hoxey and Shah, 2000; Shah et al., 2001). The finding that rates for violent methods of suicide were higher in older males than females, have also been previously observed (Shah and De, 1998; Harwood et al., 2000; Hoxey and Shah, 2000; Tadros and Salib, 2000; Salib and Green, 2003). However, this study also found that older men had higher rates of drowning than older women, which although supporting the findings of Hoxey and Shah (2000), was contrary to the results of Harwood et al. (2000), who found that this method was more common in older women than men.

This study did not support previous findings that elderly women use more passive methods of suicide (Hoxey and Shah, 2000; Harwood et al., 2000; Tadros and Salib, 2000). Although rates for poisoning by antiepileptic, sedative-hypnotic, anitparkinsonism and psychotropic drugs were higher in older women than men, these result were non significant. In addition, for all other forms of suicide by poisoning the rates were higher for older men than women, but again these were non significant.

The finding that overall rates were significantly higher in older than younger men was as expected, as traditionally suicide rates increase with ageing (Shah and De, 1998). A similar trend was found for females, although these did not reach statistical significance. However, there were no significant differences in the method of suicide used by the elderly compared to the young, for either males or females, as were found in a previous study (Tadros and Salib, 2000).

The results of this current study support the view that the U.K. government should be targeting the elderly in order to meet its suicide reduction targets (Department of Health, 1999). The differences in the methods of suicide between older men and women, and older and younger adults of both sexes, suggest a need to develop specific preventative strategies to reduce access to these methods of suicide for different age and sex groups, in order to sustain the observed decline in elderly suicide rates.

\section{Acknowledgments}

We are grateful to the University of Central Lancashire for funding LB as a student intern to conduct this research. 


\section{References}

Dennis, M. and Lindesay, J. (1995). Suicide in the elderly: the United Kingdom perspective. International Psychogeriatrics, 7, 263-274.

Department of Health (1999). Saving Lives: Our Healthier Nation. (Cm 4386). London: Stationery Office.

Harwood, D. M. J., Hawton, K., Hope, T. and Jacoby, R. (2000). Suicide in older people: mode of death, demographic factors, and medical contact before death International Fournal of Geriatric Psychiatry, 15, 736-743.

Hoxey, K. and Shah, A. K. (2000). Recent trends in elderly suicide rates and methods in England and Wales. International fournal of Geriatric Psychiatry, 15, 274-279.

Lindesay, J. (1991). Suicide in the elderly. International fournal of Geriatric Psychiatry, 6, 355-361.

Salib, E. and Green, L. (2003). Gender in elderly suicide: analysis of coroner's inquest of 200 cases of elderly suicide in Cheshire 1989-2001. International fournal of Geriatric Psychiatry, 18, 1082-1087.

doi:10.1017/S1041610209990548

\section{National alcohol consumption and suicide rates}

Alcohol-use disorders have been reported to be associated with the risk of suicide in the general population (Schneider et al., 2009) and in the elderly (Shah and Ganesvaran, 1997). This allows identification of individuals potentially at increased risk for suicide and target preventative interventions at an individual level. Moreover, alcohol is often taken during the process of committing suicide (Conwell et al., 1990). Identification of the relationship between the national consumption of alcohol and suicide rates would support generation of public health measures to reduce the national consumption of alcohol to facilitate reduction in suicide rates. Thus, a cross-national ecological study examining the relationship between national per capita consumption of alcohol and suicide rates was undertaken.

Data on general population and elderly suicide rates for males and females were ascertained from the World Health Organisation (WHO) website (www.who.int/whois/database/mort/table1.cfm). Data were collected for the latest available year and the median (range) of this latest year across the different countries was 2001 (1991-2003). Data on the national per capita consumption of alcohol were also ascertained from the WHO website (http:// www.who.int/whosis/database/core/core_select.cfm). Previous ecological studies have reported an association between suicide rates and gross national domestic product (GDP) (Kiemo, 2004; Shah et al., 2008), per capita healthcare expenditure
Shah, A. K. (2007). The relationship between suicide rates and age: an analysis of multinational data from the World Health Organization. International Psychogeriatrics, 19, 1141-1152.

Shah, A. K. and De, T. (1998). Suicide in the elderly. International fournal of Psychiatry in Clinical Practice, 2: 3-17.

Shah, A. K., Elanchenny, N. and Collinge, T. (2001). Trends in age band-specific suicide rates in the elderly. Medicine Science and the Law, 41, 102-106.

Tadros, G. and Salib, E. (2000). Age and methods of fatal self-harm (FSH). Is there a link? International fournal of Geriatric Psychiatry, 15, 848-852.

LAURA BUCKLEY ${ }^{1}$ AND AJIT SHAH ${ }^{1,2}$
${ }^{1}$ International School for Communities, Rights and
Inclusion, University of Central Lancashire, Preston,
U.K.
${ }^{2}$ West London Mental Health NHS Trust, London,
U.K.
Email: ajit.shah@wlmht.nhs.uk

(Shah et al., 2008) and divorce rates (Leenaars and Lester, 1999; Lester, 1999). Thus, the relationship between national per capita alcohol consumption and suicide rates in the general population and the elderly in the age-bands $65-74$ and $75+$ years for both sexes was examined using partial correlations because this method allowed controlling for GDP, per capita healthcare expenditure and divorce rates. Data on GDP and per capita healthcare expenditure was ascertained from the WHO website (http://www. who.int/whosis/database/core/core select.cfm) for the year 2002. Data on the rates of marriage and divorce were obtained from the United Nations Demographic Yearbook (www. unstats.un.org/unsd/demographic/products/dyb/ dyb2006) for the year 2002 .

Full data sets were available for 52 countries. The partial correlations between national per capita alcohol consumption and both general population and elderly suicide rates are illustrated in Table 1.

Table 1. Correlation between alcohol consumption and suicide rates

\begin{tabular}{|c|c|c|}
\hline SUICIDE RATE & CORRELATION & \\
\hline GROUP & COEFFICIENT & P VALUE \\
\hline \multicolumn{3}{|l|}{ Males } \\
\hline General population & 0.28 & 0.044 \\
\hline $65-74$ years & 0.24 & 0.08 \\
\hline $75+$ years & 0.30 & 0.029 \\
\hline \multicolumn{3}{|l|}{ Females } \\
\hline General population & 0.2 & 0.15 \\
\hline $65-74$ years & 0.15 & 0.28 \\
\hline $75+$ years & 0.21 & 0.12 \\
\hline
\end{tabular}

